\title{
Simulation Tests on Load Bearing Features of Mudstone Foundation in Project Lifecycle
}

\author{
Furong $\mathrm{Ma}^{1}$, Huan $\mathrm{Luo}^{1 *}$, Yi Liao ${ }^{1}$, Xingui Zhang ${ }^{2}$ \\ ${ }^{1}$ College of Civil Engineering, Guangxi Vocational Normal University, Nanning 530007, China \\ ${ }^{2}$ College of Civil Engineering and Architecture, Guangxi University, Nanning 530004, China
}

Corresponding Author Email: luohuan802020@163.com

https://doi.org/10.18280/ijdne.150410

Received: 28 March 2020

Accepted: 3 June 2020

\section{Keywords:}

mudstone, load bearing features, project lifecycle, soft rock

\begin{abstract}
This paper attempts to identify the load bearing features of the homogeneous hard mudstone foundation, which has been softened into a soft and hard interbedded foundation under external factors, throughout the project lifecycle. For this purpose, a homogeneous hard mudstone foundation was prepared indoor through compaction, and soaked in water to simulate the mudstone foundation in construction site. Then, the homogeneous hard mudstone foundation and the soft and hard interbedded foundation were separately subject to shallow plate static load tests. During the tests, it was observed that the mudstone foundation was greatly affected by environmental changes during project lifecycle, and the load bearing capacity of the mudstone foundation dropped by over $60 \%$ after being soaked in water. This means water action has a prominent impact on mudstone foundation in the project lifecycle; the loading bearing capacity of mudstone foundation could be greatly weakened by soaking in construction water or rainwater. Therefore, the load bearing capacity of mudstone foundation must be tested and evaluated timely in the construction period.
\end{abstract}

\section{INTRODUCTION}

Mudstone is different from ordinary rocks, and its physical and mechanical properties are significantly different from ordinary rocks [1]. Due to the special properties of mudstone in Nanning Basin, such as short diagenesis time, poor cementation, semi-consolidated diagenesis state, rock-like but it's not rock, soil-like but it's not soil, soft and hard layers deposited alternately, easy to weather, poor water stability, shrinks when loses water, swells when contacts water, and then softens and disintegrates; moreover, the natural uniaxial compressive strength is low, generally between $0.2-9.4 \mathrm{MPa}$ [2]. In the construction process of engineering projects, research on the properties of mudstone is a necessity. Project lifecycle refers to the construction period and the operation period. The engineering problems of mudstone within the project lifecycle mainly include the softening of the mudstone stratum after being soaked by construction water, or exposed to rainwater for a long-time during construction in rainy seasons, or the lowering in the bearing capacity of the bearing stratum caused by infiltrated surface water and soaked foundation, which would result in excessive or uneven settlement of the structure, etc. Within the project lifecycle, if the mudstone layer is softened and the foundation is weakened, it will directly affect the safety of the engineering project and increase the construction cost, the built structure might crack or even collapse in severer cases.

For the engineering problems of mudstone in project lifecycle, scholars have conducted various relevant research. In terms of the interaction between mudstone and water, Yoshida et al. [3] studied the unloading and softening of tertiary mudstone, which deteriorated and its strength decreased over time. Dehnavi and Sadeghi [4] conducted research on the mechanical properties of claystone, and pointed out that claystone is easily eroded by water, which significantly affects its physical and mechanical properties, and changes its engineering properties to a certain extent. Zeng, et al. [5] studied the physical and mechanical properties of strongly weathered mudstone after it's subject to three cycles of drying-and-wetting, freezing-and-thawing, and drying-andwetting, and believed that the cyclic environment has a great impact on the microstructure, stress-strain behavior, and shear strength of the samples. In terms of the mechanical properties, and failure and deformation characteristics of the interbedded mudstone, Wang et al. [6] applied the failure theory of the stratified rock mass to study the strength and failure characteristics of sandstone interbedded with mudstone interlayers through uniaxial tests, revealing that the mechanical properties and failure mechanism of sandstone interbedded with mudstone. Taheri and Tani [7] used a downhole triaxial test method to study the shear strength and deformation ability of the mudstone interbedded with sandstone, and the results showed that the sandstone interlayers caused the shear strength and deformation characteristics of the mudstone to decrease to varying degrees. Pham et al. [8] conducted uniaxial compression tests on mudstone samples with different water contents to analyze the impact of unsaturated and re-saturated states on the mechanical properties of mudstone. Taheri and Tani [9] proposed a small hole in-situ triaxial test method to measure the shear strength and deformation ability of soft sedimentary rocks. To study the impact of soft and weak layers on the mechanical properties of interbedded mudstone and effectively improve the reliability of its mechanical parameters, considering that it's hard to obtain complete samples of soft and weak layer interbedded mudstone, Ma et al. [2] adopted 
an indoor compaction method to fabricate mudstone samples with regular layered structures, and conducted uniaxial tests on it to compare and analyze the strength and deformation characteristics of the samples. Zheng et al. [10] used physical model tests and discrete element method to study the failure mechanism of sandstone-mudstone interbedded slopes, and believed that the wetting and softening of mudstone is one of the main factors causing landslides. In terms of the swelling characteristics of mudstone when contacts water, $\mathrm{R}$. Doostmohammadi et al. [11] studied the effect of wet-and-dry cycles on the swelling strain and swelling pressure of mudstone, and believed that increasing the number of wet-anddry cycles can shorten the time required for the final expansion of mudstone. Zeng et al. [12] adopted bearing plate tests to study the impact of water content and wet-and-dry cycles on the swelling characteristics of carbonaceous mudstone. Mohajerani et al. [13] also studied the swelling properties of claystone. In addition, Mondol et al. [14] studied the changes in the physical properties of mudstone during the burial process. Wan et al. [15] studied the engineering properties, durability and weathering speed of silty mudstone with different degrees of weathering.

The above-mentioned research mainly focused on aspects such as the physical mechanics of mudstone, water-rock interaction, and swelling characteristics, etc., and rarely involved the bearing characteristics of hard mudstone softened into hard and soft layers under the influence of the external environment. Since mudstone has the characteristics of swelling and softening when contacts water, and shrinking when it loses water, it is often disturbed during the construction process, resulting in reduction in the bearing capacity. Therefore, studies on the impact of external environmental factors on the transformation of homogeneous hard mudstone foundation into soft-hard interbedded mudstone foundation in the project lifecycle, and the bearing characteristics of softened homogeneous hard mudstone foundation are conductive to instructing design and construction. At present, the research on the engineering properties of mudstone mainly focuses on the characteristics and properties before construction, while there's few studies concerning the properties of mudstone within the project lifecycle. In order to clarify the changes in the properties of mudstone within the project lifecycle, this study adopted physical model to conduct shallow plate static load tests, used compaction method to fabricate homogeneous hard mudstone foundation, and conducted static load tests on it. At the same time, the prefabricated hard mudstone samples were soaked in water to soften the mudstone, forming soft and hard interbedded mudstone foundation, which was then subject to the static load test to compare the bearing characteristics of the mudstone foundation under the two conditions, and study the changes in the bearing capacity of the mudstone foundation at the initial stage of soaking $(24 \mathrm{~h})$.

\section{TEST PLAN}

\subsection{Test design}

Fabrication of hard mudstone foundation: a high-strength $P E$ pipe with an inner diameter of $20.5 \mathrm{~cm}$ and a height of $50 \mathrm{~cm}$ was taken as the container to compact the mudstone layer to a thickness of $40 \mathrm{~cm}$, and remaining $10 \mathrm{~cm}$ in the PE pipe was filled with water. According to the test code of the shallow plate static load tests, the width of the test pit was 3 times the diameter or width of the bearing plate. Therefore, this test adopted steel plate with a diameter of $7 \mathrm{~cm}$ and a thickness of $2 \mathrm{~cm}$ as the bearing plate.

This test mainly compared the changes in the bearing characteristics of mudstone foundation before and after it's soaked in water, the shallow plate static load tests were conducted mainly from the following two aspects:

(1) Reference test: it's the physical model test on the bearing capacity of homogeneous hard mudstone foundation. The samples of homogeneous hard mudstone layer were fabricated in a test barrel, and then the static load test was performed on the surface of the hard mudstone foundation.

(2) Comparation test: it's the physical model test on the bearing capacity of the soft and hard interbedded mudstone foundation after being soaked and softened in water. This test simulated the foundation soaked in construction water, which can result in foundation softening. According to previous studies, the water soaking time for the complete disintegration of Nanning Basin mudstone is 24 hours [16]. Based on this result, $10 \mathrm{~cm}$ water was injected into the sample barrel, and the sample was soaked for $24 \mathrm{~h}$ to form a soft and hard interbedded mudstone foundation. When the soaking time was reached, excess water in the sample barrel was drained, and the static load test was performed.

The test model is shown in Figure 1. In order to reduce the impact of the inhomogeneity of manual sample preparation on the test results, 6 samples were fabricated for the reference and comparison tests.
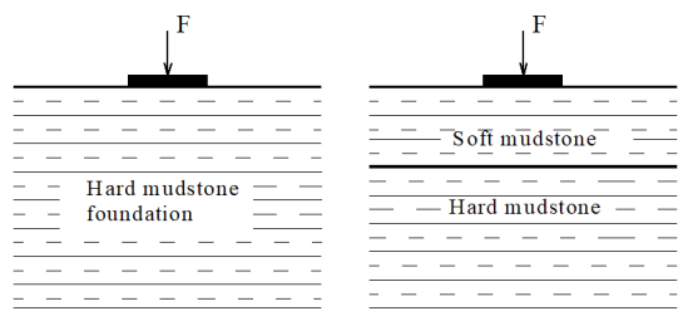

Figure 1. Foundation model of shallow plate load test

\subsection{Measurement system and loading/unloading regulations}

The loading system of this test was modified by arranging double-linked consolidation apparatus in series, the leverage ratio was 12:1, as shown in Figure 2.

First, the bearing capacity of the mudstone foundation was estimated with the loading effect taking into consideration, and the loads of the reference and the comparison tests were estimated as well. For the reference tests, the loading weight of each level was $3 \mathrm{~kg}$, according to the leverage ratio and the diameter of the load plate, the converted load of each level acting on the mudstone layer was $187 \mathrm{kPa}$. For the comparison tests, the loading weight of each level was $1.5 \mathrm{~kg}$, again according to the leverage ratio and the diameter of the load plate, the converted load of each level acting on the mudstone layer was $94 \mathrm{kPa}$.

The load was applied slowly to maintain the loading weight as steady as possible, under the action of the load of each level, dial indicator readings were recorded at $10 \mathrm{~min}, 10 \mathrm{~min}, 10 \mathrm{~min}$, $15 \mathrm{~min}$, and $15 \mathrm{~min}$ intervals, and then measured and recorded every $30 \mathrm{~min}$ afterwards. Within two consecutive hours, when the settlement per hour was less than $0.1 \mathrm{~mm}$, the load of the next level was applied. When under the load of a certain level, 
the settlement rate within $24 \mathrm{~h}$ could not reach the stable standard, or the ratio of the settlement amount to the width or diameter of the bearing plate was greater than or equal to 0.06 , the loading was terminated.

The test equipment and instruments are shown in Figure 3.

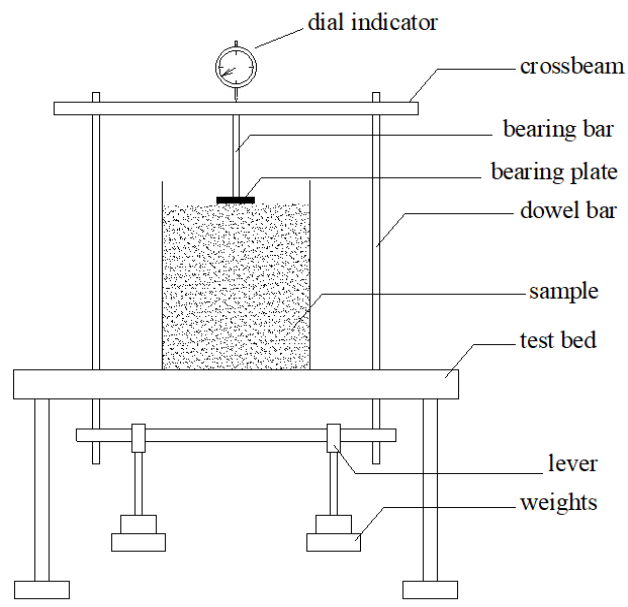

Figure 2. Load measurement system

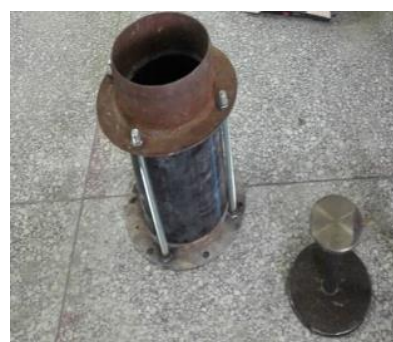

(a) Sample preparation device

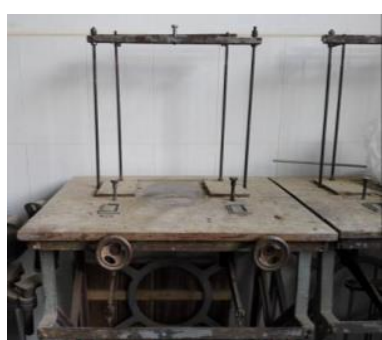

(b) Test bench
Figure 3. Test equipment

\subsection{Sample production}

By airing, crushing and sieving the collected samples, the samples with a water content of $15 \%$ were prepared and stood airtightly for one day and one night for later use. After that, the fabricated samples were subject to the tests and the parameters are shown in Table 1 below.

Table 1. Physical and mechanical parameters of the mudstone

\begin{tabular}{|c|c|c|c|}
\hline Category & $\begin{array}{c}\text { Water content } \\
\omega(\mathbf{\%})\end{array}$ & $\begin{array}{c}\text { Density } \boldsymbol{\rho} \\
\left(\mathbf{g} \cdot \mathbf{c m}^{-3}\right)\end{array}$ & $\begin{array}{c}\text { Porosity } \\
\text { ratio e }\end{array}$ \\
\hline Mudstone & 15.07 & 2.185 & 0.4325 \\
\hline $\begin{array}{c}\text { liquidity } \\
\text { index } \mathbf{I}_{\mathbf{L}}\end{array}$ & $\begin{array}{c}\text { Internal friction } \\
\left.\text { angle } \boldsymbol{\varphi} \mathbf{(}^{\circ}\right)\end{array}$ & $\begin{array}{c}\text { cohesion } \\
\text { force } \boldsymbol{c}(\mathbf{k P a})\end{array}$ & $\begin{array}{c}\text { Permeability } \\
\text { coefficient } \\
\left(\times \mathbf{1 0}^{-8} \mathbf{c m} / \mathbf{s}\right)\end{array}$ \\
\hline-0.12 & 18 & 85 & 1.74 \\
\hline
\end{tabular}

The prepared samples were separated into three layers and compacted, the surface between layers were roughened with a scraper, the fabrication process is shown in Figure 4.

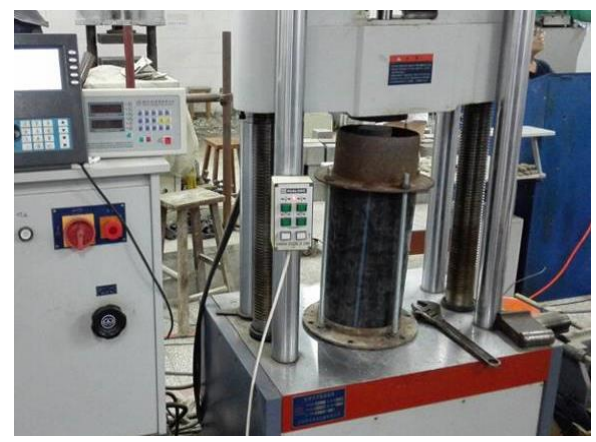

Figure 4. Sample preparation

\section{SIMULATION TESTS ON THE BEARING CHARACTERISTICS OF HOMOGENEOUS HARD MUDSTONE FOUNDATION}

\subsection{Test steps}

First, the processed sample barrel was place on the test bench, and leveled with medium sand, then the bearing plate and force transfer column were installed, and the force transfer rod was connected; after that, a dial indicator was installed on the beam, the loading lever was adjusted, and a $1 \mathrm{kPa}$ weight was applied to make all parts in close contact, and the dial indicator was adjusted to zero. Finally, the loads were applied level by level according to loading requirements, and the settlement amount was recorded.

\subsection{Test results and analysis}

The static load tests of the homogeneous hard mudstone foundation gave 6 load and displacement curves, as shown in Figure 5. The test results of each sample are shown in Table 2. It can be seen from Table 2 that the results of sample 5\# were smaller than those of other samples, indicating that there's a problem with the preparation of the sample, the data was abnormal and should be eliminated. After that, the average values of samples $1 \#, 2 \#, 3 \#, 4 \#$, and $6 \#$ were taken as the representative value of the homogeneous hard mudstone foundation, and the representative $\mathrm{p}$-s curve for static load test of the homogeneous hard mudstone foundation is shown in Figure 6.

It can be seen from Figure 6 that the p-s curve dropped sharply when the load was applied to $1122 \mathrm{kPa}$. When the load was applied to $1309 \mathrm{kPa}$, the settlement rate cannot reach the stable standard within $24 \mathrm{~h}$, so the limit bearing capacity of the homogeneous hard mudstone foundation was $1122 \mathrm{kPa}$.

Table 2. Test results of homogeneous hard mudstone foundation under static load

\begin{tabular}{cccccccc}
\hline Samples & Sample 1\# & Sample 2\# & Sample 3\# & Sample 4\# & Sample 5\# & Sample 6\# & Representative value \\
\hline Limit bearing capacity/kPa & 1122 & 1122 & 1122 & 1122 & 935 & 1122 & 1122 \\
Total settlement $/ \mathrm{mm}$ & 9.71 & 10.10 & 9.21 & 10.99 & 12.18 & 11.97 & 10.46 \\
\hline
\end{tabular}




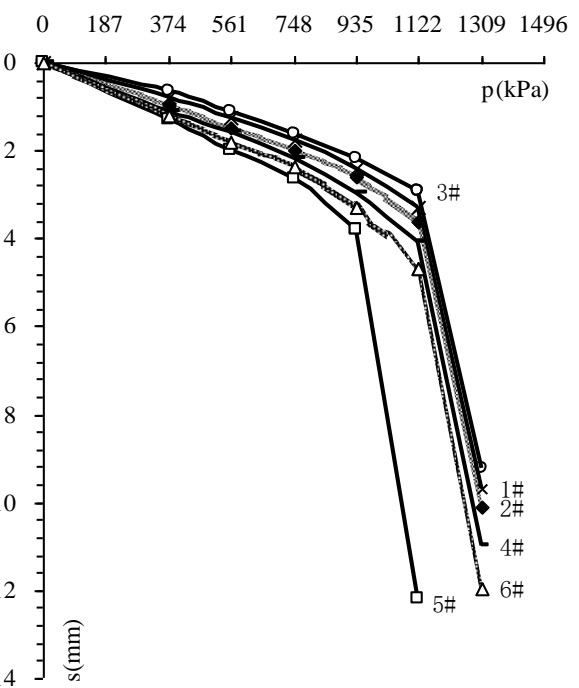

Figure 5. P-S curves of static load test of homogeneous hard mudstone foundation

\section{SIMULATION TEST ON THE BEARING CHARACTERISTICS OF SOFTENED HARD MUDSTONE FOUNDATION}

The model test mainly studied the load-bearing characteristics of the homogeneous hard foundation softened into soft-and-hard interbedded foundation caused by construction water or external environment.

\subsection{Test steps}

After the hard mudstone was compacted, water was poured into the sample barrel, the height of the water was $10 \mathrm{~cm}$, the mudstone was soaked for $24 \mathrm{~h}$ under normal water level, after that, the water in the sample barrel was drained, and samples were taken from the section of the mudstone to measure the water content. After that, the sample barrel was placed on the loading platform, and the end surface was leveled with medium, then the bearing plate and force transfer column were installed, the force transfer rod was connected, a dial indicator was installed on the beam, and the loading lever was adjusted. Finally, the static load test was performed.

\subsection{Test results and analysis}

For the six tests, soaking and softening process was performed to build soft-and-hard interbedded mudstone foundation, and test curves of the static load tests of the softand-hard interbedded mudstone foundation were obtained as shown in Figure 7. The bearing capacity and total settlement of each sample are shown in Table 3. It can be seen from Figure 7 that the uniformity of the sample was good, and the average value of 6 test results was taken as the representative value of the static load test of the softened hard foundation. The representative $\mathrm{p}$-s curve of static load test of soft and hard interbedded mudstone foundation is shown in Figure 8. At the same time, after water soaking, 6 samples were prepared for water content test. The average water content of the 6 samples was $17.31 \%$, which had increased by $2.24 \%$ compared with the initial water content.

It can be seen from Figure 8 that the p-s curve dropped sharply when the load was applied to $376 \mathrm{kPa}$. When the load

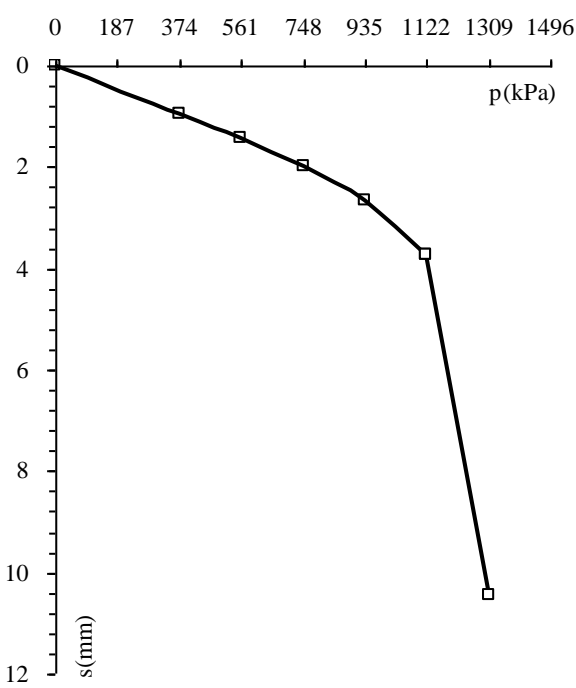

Figure 6. Representative p-s curve of static load test of homogeneous hard mudstone foundation

was applied to $470 \mathrm{kPa}$, the settlement rate cannot reach the stable standard within $24 \mathrm{~h}$, so the limit bearing capacity of the soft and hard interbedded mudstone foundation was $376 \mathrm{kPa}$.

Through static load tests on homogeneous mudstone foundations and soft and hard interbedded mudstone foundations softened by water, the softening phenomenon of hard mudstone layers in project lifecycle was simulated, their bearing characteristics were studied, and the changes in the bearing capacity of softened mudstone foundation in the initial soaking stage were analyzed. The simulation test showed that the limit bearing capacity of homogeneous hard mudstone foundation was $1122 \mathrm{kPa}$, the maximum cumulative settlement was $10.46 \mathrm{~mm}$; the limit bearing capacity of the hard layer softened into soft and hard mudstone foundation was $376 \mathrm{kPa}$, and its maximum cumulative settlement was $14.28 \mathrm{~mm}$. The comparison showed that the limit bearing capacity of the water-soaked mudstone foundation was $746 \mathrm{kPa}$ smaller than that of the un-soaked mudstone foundation, decreased by $66.5 \%$, and the maximum cumulative settlement increased by $26.8 \%$. This test showed that the bearing capacity of mudstone foundation at the initial stage of water-soaking had decreased sharply by more than $60 \%$, this is because the samples in this simulation test were remodeled samples, which were different from the original mudstone. The original structure of the mudstone was destroyed, so the water stability was worse, and the action of water and rock was more significant, resulting in a sharp decrease in the bearing capacity of mudstone foundation after water-soaking. The test results showed that under the condition that mudstone had interacted with water for $24 \mathrm{~h}$, the bearing capacity suddenly decreased by more than $60 \%$. At the same time, the test results also showed that, after soaked in construction water or rainwater, the soaked parts of the samples should be processed before the next procedure, so as to ensure that the bearing capacity of the mudstone foundation can meet the requirements and safety could be ensured. It can be seen that the external environment has a great impact on the mudstone stratum in the project lifecycle, especially the construction water and rainwater have a great impact on the bearing capacity of the mudstone foundation, which would greatly weaken the bearing capacity of the structure, therefore, it should be noted to process the soft and weak layers first during construction. 


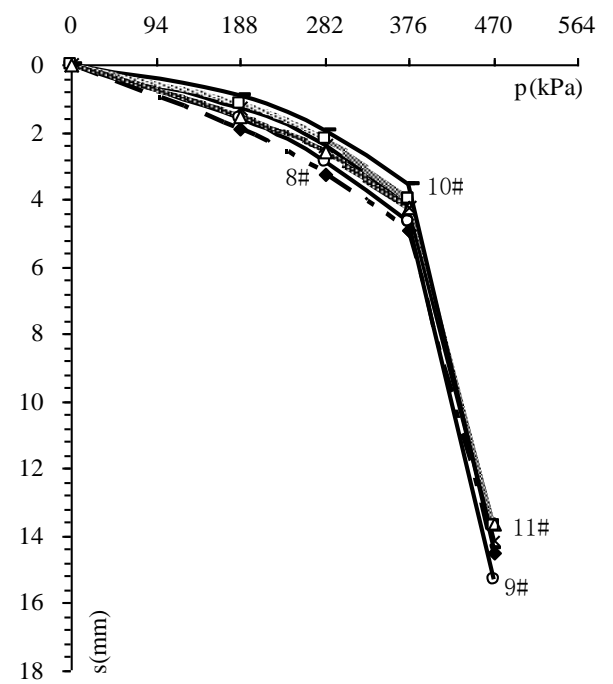

Figure 7. P-s curves of static load test of softened hard mudstone foundation

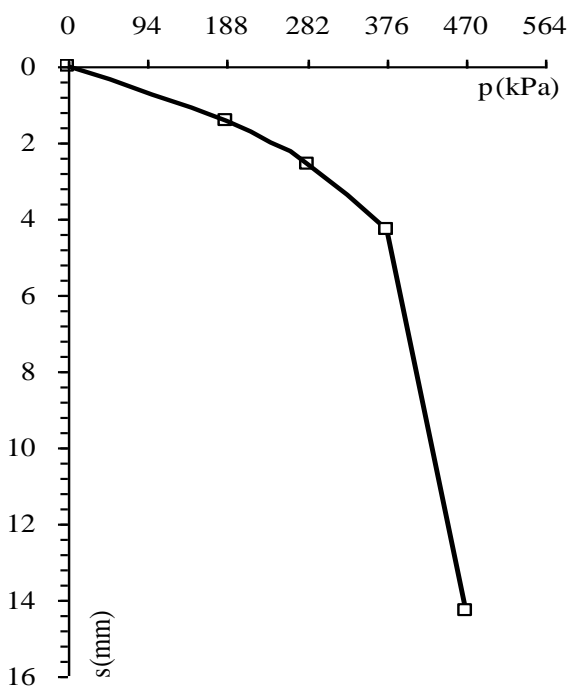

Figure 8. Representative p-s curve of static load test of softened hard mudstone foundation

Table 3. Test results of softened hard mudstone foundation under static load

\begin{tabular}{cccccccc}
\hline Samples & Sample 7\# & Sample 8\# & Sample 9\# & Sample 10\# & Sample 11\# & Sample 12\# & Representative value \\
\hline Limit bearing capacity $/ \mathrm{kPa}$ & 376 & 376 & 376 & 376 & 376 & 376 & 376 \\
Total settlement $/ \mathrm{mm}$ & 14.13 & 14.51 & 15.27 & 14.38 & 13.73 & 13.65 & 14.28 \\
\hline
\end{tabular}

\section{CONCLUSION}

Within the project lifecycle, the impact of environmental changes on mudstone stratum is prominent, especially the action of water has a great impact on it, therefore the effect of construction water on the force bearing layer should not be ignored during project lifecycle, and safety measures for ensuring the strength of the foundation should be adopted. Within the project lifecycle, the softening of the hard mudstone layer weakened the bearing capacity of the stratum, and the decrease can exceed $60 \%$ at the initial stage of watersoaking $(24 \mathrm{~h})$, therefore, protection of mudstone foundation during construction should be strengthened, and soft and weak layers caused by construction water or rainwater should be removed completely; at the same time, test and evaluation on the bearing capacity of force bearing layers should be carried out; to ensure engineering safety, the next procedure should be carried out only after all requirements are met.

\section{ACKNOWLEDGMENT}

This work was financially supported by the Guangxi Natural Science Foundation (Grant No.: 2011GXNSFB018002). And Guangxi basic capacity promotion project for Middle-aged and young teachers in colleges (Grant No.: KY2016YB586).

\section{REFERENCES}

[1] Douma, L.A.N.R., Primarini, M.I.W., Houben, M.E., Barnhoorn, A. (2017). The validity of generic trends on multiple scales in rock-physical and rock-mechanical properties of the Whitby Mudstone, United Kingdom. Marine and Petroleum Geology, 84: 135-147. https://doi.org/10.1016/j.marpetgeo.2017.03.028

[2] Ma, F., Zhang, X., Yi, N. (2017). Stratiform Compound Mudstone Mass under Uniaxial Compression. Modelling, Measurement and Control B, 86(2): 427-437. https://doi.org/10.18280/mmc_b.860208

[3] Yoshida, N., Nishi, M., Kitamura, M., Adachi, T. (1997). Analysis of mudstone deterioration and its effect on tunnel performance. International Journal of Rock Mechanics and Mining Sciences, 34(3-4): 353.e1353.e19. https://doi.org/10.1016/S1365-1609(97)00289$\mathrm{X}$

[4] Dehnavi, R.N., Sadeghi, M. (2019). Deterioration of weak rocks over time and its effect on designing tunnel support systems. Bulletin of Engineering Geology and the Environment, 78(2): 1045-1056. https://doi.org/10.1007/s10064-017-1154-9

[5] Zeng, Z., Kong, L., Wang, M., Sayem, H.M. (2018). Assessment of engineering behaviour of an intensely weathered swelling mudstone under full range of seasonal variation and the relationships among measured parameters. Canadian Geotechnical Journal, 55(12): 1837-1849. https://doi.org/10.1139/cgj-2017-0582

[6] Wang, C., Kou, H., Han, W. (2019). Mechanical properties and failure mechanism of sandstone with mudstone interlayer. In E3S Web of Conferences, pp. 136 : 04048 . https://doi.org/10.1051/e3sconf/201913604048

[7] Taheri, A., Tani, K. (2008). Use of down-hole triaxial apparatus to estimate the mechanical properties of heterogeneous mudstone. International Journal of Rock Mechanics and Mining Sciences, 45(8): 1390-1402. https://doi.org/10.1016/j.ijrmms.2008.01.017

[8] Pham, Q.T., Vales, F., Malinsky, L., Minh, D.N., Gharbi, H. (2007). Effects of desaturation-resaturation on mudstone. Physics and Chemistry of the Earth, Parts A/B/C, 32(8-14):

646-655. 
https://doi.org/10.1016/j.pce.2006.03.012

[9] Taheri, A., Tani, K. (2010). Characterization of a sedimentary soft rock by a small in-situ triaxial test. Geotechnical and Geological Engineering, 28(3): 241249. https://doi.org/10.1007/s10706-008-9245-9

[10] Zheng, Y., Chen, C., Liu, T., Zhang, W., Song, Y. (2018). Slope failure mechanisms in dipping interbedded sandstone and mudstone revealed by model testing and distinct-element analysis. Bulletin of Engineering Geology and the Environment, 77(1): 49-68. https://doi.org/10.1007/s10064-017-1007-6

[11] Doostmohammadi, R., Moosavi, M., Mutschler, T., Osan, C. (2009). Influence of cyclic wetting and drying on swelling behavior of mudstone in south west of Iran. Environmental Geology, 58(5): 999. https://doi.org/10.1007/s00254-008-1579-3

[12] Zeng, L., Li, F., Liu, J., Gao, Q., Bian, H. (2019). Effect of initial gravimetric water content and cyclic wettingdrying on soil-water characteristic curves of disintegrated carbonaceous mudstone. Transportation Safety and Environment, 1(3): 230-240. https://doi.org/10.1093/tse/tdz018
[13] Mohajerani, M., Delage, P., Monfared, M., Tang, A.M., Sulem, J., Gatmiri, B. (2012). On the resaturation of swelling claystone. In: Mancuso C., Jommi C., D’Onza F. (eds) Unsaturated Soils: Research and Applications. Springer, Berlin, Heidelberg, 411-417. https://doi.org/10.1007/978-3-642-31116-1_56

[14] Mondol, N.H., Bjørlykke, K., Jahren, J., Høeg, K. (2007). Experimental mechanical compaction of clay mineral aggregates-Changes in physical properties of mudstones during burial. Marine and Petroleum Geology, 24(5):

289-311. https://doi.org/10.1016/j.marpetgeo.2007.03.006

[15] Wan, S.M., Wu, Q.H., Yang, Y.L. (2012). Research the Weathering Characteristics of Tertiary Silty Mudstone along Chengnan Freeway. In Advanced Materials Research, 446-449: 1127-1131. https://doi.org/10.4028/www.scientific.net/AMR.446449.1127

[16] Lu, Z.Q. (2015). Experimental study on the mechanical properties of hole bottom softening of nanning argillaceous rocks. Nanning: Guangxi Uiversity, 2015: 32-35. https://doi.org/10.7666/d.Y3087750 